\title{
The Potential of Carbon-Nano Based Electrical Energy Storage Systems to Upgrade the Solar Energy Generation in Zimbabwe
}

\author{
Pardon S. Mutanda*, Rutendo J. Pawandiwa, and Eubert P. Mahofa \\ Departement of Chemical and Process Systems Engineering, \\ School of Engineering and Technology, \\ Harare Institute of Technology, Harare Zimbabwe \\ \{mutandapardonsimbarashe, pawandiwajean\} @gmail.com, \\ eubertmahofa@gmail.com
}

\begin{abstract}
Efficient energy generation and utilization of both energy resources and energy by the end user will play a significant role in the socio-economic development and generation of wealth in Zimbabwe. One of the most promising renewable energy source in the country is Solar Energy. In recent years, solar energy has received much attention as an easily utilizable energy source of electricity. If proper systems and technology are used, solar energy can provide an environmental friendly option and national energy security for a long-term sustainability of the Zimbabwean economy. This paper describes the potential of Advanced Solar Energy Generation by integrating Nano Carbon Electrical Energy Storage System to improve the energy sector in Zimbabwean perspective.
\end{abstract}

Keywords: Carbon Nano Materials (CNM), Electrical Energy Storage (EES), Ultracapacitors.

\section{Introduction}

It is important to realize that improving Zimbabwe's economy even the whole of Africa, is increasing energy demand per person by more than ten times that which is currently being produced. With hydrocarbons being the backbone of our energy generation infrastructures, environmental degradation will increase exponentially. That is why there is a great need of sustainable power generation system (renewable energy), for a successful economic development and a better environment. Solar Power is clean and eco-friendly renewable energy technology that can play an important role in a securing the future of Zimbabwe's energy.

*Pardon S. Mutanda, E-mails: mutandapardonsimbarashe@gmail.com (Pardon S. Mutanda), pawandiwajean@gmail.com (Rutendo J. Pawandiwa) and eubertmahofa@gmail.com (Eubert P. Mahofa) 
The solar energy that is received by the earth's surface every year is more than 10.000 times over the global requirement [5]. Therefore, with large solar power plants, it is possible to harvest the sun's energy especially in Zimbabwe which has savanna regions as most of its land, which has sun almost throughout the year. Although over the years, the solar industry has been constantly evolving, and improving becoming more efficient and cheaper, it has to be more cheaper and better than it is today to fully penetrate the markets like Africa [10].

Not only does it have to be made cheaper, but improvements have to be done on energy delivery and utilization on the solar power systems so that they become more sustainable than they are today. The major drawback in solar technology is to find a way to provide power to our homes and appliances throughout the day (day and night) no matter the weather. Solving this issue and others is a major step in advancing solar energy generation. One way of doing it is employing advanced Energy Storage systems that customers can use and rely on all the times.

Electrical Energy Systems, are advanced energy storage system that can fill in the gap and address two of the characteristics of electricity: First is that, electricity is consumed at the instant it is created and the second is that since power is usually generated far from the consumer, and is connected by power lines from generation to consumer, at times power may be concentrated in one line (congestion) which results in variations and power cuts [15]. EES can provide the balance required between peak hours and stability and a constant quality (voltage and frequency), making them ideal in the solar power generation.

Power demand changes every time during the day and its price is high during peak hours. EESs can benefit consumers during peak-demands since it stabilizes power at peak hours. Not only does it benefit financially but also it ensures a continuous and flexible supply of power even when there is a long distance between generation and consumption of the electrical energy [15].

Integration of EES in the Zimbabwe will result in Smart Grids that will benefit the nation as a whole. EES can be installed in customer-side substations and control and monitor the electrical energy flow to the consumers or as the energy storage medium for Energy Management Systems (EMS) in homes and buildings.

\subsection{Solar Energy Generation}

Solar radiation that reaches the earth's surface can be utilized in two most popular technologies: Solar Thermal Power and Solar Power Systems. Solar thermal systems use solar radiation to generate heat - as hot water, hot steam or hot air etc. to generate the energy required for most of our daily activities such as power generation, cooking, heating and cooling. Though being used already at a large scale in countries like Australia and India etc. there is still more room for making the system more effective [4]. This technology can be classified into two types: Non-Concentrating or concentrating but can be applied as a stationary or with sun-tracking mechanism depending on application, temperature required and economic viability.

Solar power utilizes sunlight to generate energy that can be used for many applications. Solar photovoltaic cells (on solar panels) converts sunlight energy and produce an electrical current that can drive a load. When a photon hits the surface of 
the solar panel (with silicon atoms), it knocks off electrons this is what create the electrical current. An inverter is used to convert the Direct Current (DC) voltage to an Alternating Current (AC) and feeds energy it to where it is required. Both photovoltaics and solar thermal power plants have been tested and proven their feasibility and have many references around the world [6].

It is a good thing that solar power industry is growing and being applied to large scale application in most countries. The industry is expected to continue to rise up until 2030 due to reduced need of energy for heating and cooling in most applications as shown in Table 1. The reduction is based on the assumption that the efficiency of most energy consuming performance of most building and electrical appliances will have greatly improved [8].

Table 1. Expected growth rates for Solar Thermal Energy.

\begin{tabular}{lll}
\hline $\mathbf{2 0 1 0 - 2 0 2 0}$ & $\mathbf{2 0 2 0 - 2 0 3 0}$ & $\mathbf{2 0 3 0 - 2 0 3 0}$ \\
\hline $16 \%$ & $14 \%$ & $7 \%$ \\
\hline
\end{tabular}

Making solar power generation cheap will make it more adoptable to most parts of the world increasing its energy share, especially in developing countries like Zimbabwe which receives plenty of the sun's radiation during the year (Fig. 1).

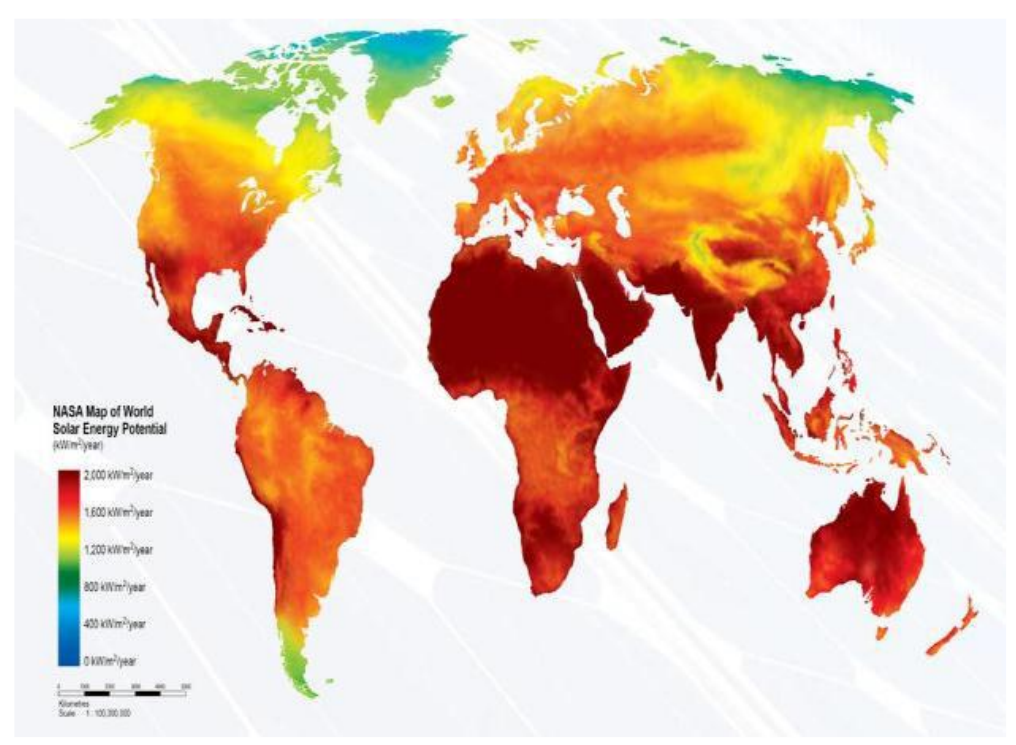

Fig. 1. Solar Energy Potential.

Solar energy is already being explored in Zimbabwe and already the Zimbabwe Power Company (ZPC) is planning to build a 300MW Solar Power Station in Gwanda, Zimbabwe [16]. However, one way of ensuring sustainability and energy security as well as success of these solar projects around the country, is to upgrade the 
grid with energy storage devices which are capable of effectively store and deliver electrical energy when need called Electrical Energy Storage Devices (EES). These devices can be installed for s can be private (home energy storing device) or a storage station.

\subsection{Electrical Energy Storage Systems}

Energy can be stored and delivered as electrical energy in two ways, using batteries and electrochemical capacitors. For large scale applications like national power grid energy storing devices, any ordinary battery will not be capable of working effectively. At the same time, a battery which is big but have poor energy capacity to battery mass ratio $(\mathrm{Wh} / \mathrm{kg})$ will not be effective in terms of amount of electrical energy stored and cost of the system.

Today lithium ion batteries are most commonly used and preferred energy storing devices around the world, however they have disadvantages, though they have a high energy capacity to mass ratio. Lithium batteries have a short life cycle and are explosive and toxic. Many approaches have been taken to improve the lithium ion cell but it still has low power density [2]. Recently, a giant mobile company SAMSUNG® attempted to increase the size of their mobile battery, and the results when catastrophe. Most of the mobile phones started to explode and forced the company to withdraw 2.2 million units from the public [11]. Nanotechnology has also been applied to the lithium cells to shorten the diffusion distances of the lithium ions and dopants to improve transportation of ions but a stable performance over thousand cycles of charge/discharge has not yet been attained [2]. Thus, making lithium ion cells not applicable as an effective EES.

Ultracapacitors are another energy storing devices that can be applied and have a great potential to replace the battery. Ultracapacitors or electrochemical capacitors are energy storage devices that have fast power delivery and long-life cycle life that can play and important role in complementing the solar power industry [13]. They do not only offer energy storage solutions in the solar industry but in most applications where batteries are required e.g. electric vehicles, aerospace engineering [2]. Compared to batteries and fuel cells, ultracapacitors hold higher coulometric efficiency (charge/discharge efficiency) and energy efficiency. They have high power density, high energy density than batteries, fuels cells and conventional capacitors, while giving a longer lifespan too. The difference is due to different energy storage mechanism ultracapacitors have [14].

Ultracapacitors can be made from carbon-nanomaterials such as graphene, carbonnanotubes (CNTs), carbon-nano onions (CNOs) etc. These nano materials have novel properties such as greater surface area, novel electrical conductivity that can be utilized in the making of a super battery that is efficient and cheap - a good candidate to upgrade the solar energy generation system. This type of battery will reduce significantly the cost of solar energy generation. Consumers will be able to store energy and use it when it is only needed, for example, charging during the day and use it at night when the sun does not shine. 


\section{Nano Carbon Based Ultracapacitors}

Ultracapacitors or Electrochemical Double Layer Capacitor (EDLC)are almost similar to conventional capacitors and are governed by the same principles, but the differences lie in that, ultracapacitors have electrodes with much higher surface areas and thinner dielectrics that decrease the gap between electrodes.

$$
\begin{aligned}
& \mathrm{C}=\varepsilon_{0} \varepsilon_{\mathrm{r}} \mathrm{A} / \mathrm{d} \\
& \mathrm{E}=0.5 \mathrm{CV}^{2}
\end{aligned}
$$

Thus, from equations 1 and 2, ultracapacitors have more capacitance and energy paper. When ultracapacitors is charged, positive ions are attracted to the cathode and the negative ions to the anode to attain a charge balance. The layer immediate to the electrode acts as a dielectric and the outside layer holds the charges. The attraction creates capacitance between ions and the surface of the electrode thus the name dual layer. This attraction occurs at both electrodes and the total capacitance is the capacitance of the two in series [9]. The intensity of the electrical field around the electrode determines the number of ions at the electrodes, which means that an increased voltage results in increased capacitance.

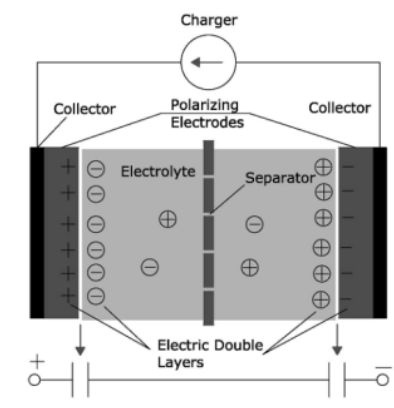

Fig. 2. Electrical Double Layer Capacitor [11]

From the surface of the electrode is a layer of conduction molecules from the electrolyte. The distance between the electrodes and the electrodes is the distance of separation hence capacitance is increased from the equation 1. Capacitance also depends on the concentration of the ions around the electrode, hence a greater surface area will increase the capacitance

\subsection{Advantages of Ultracapacitors}

Ultracapacitors have several advantages as EES devices over conventional capacitors and batteries, only a few have been mentioned in Table 2 below, however they also have their drawbacks, 
Table 2. Advantages and Disadvantages of Ultracapacitors.

\begin{tabular}{lll}
\hline & Advantages & Drawbacks \\
\hline 1 & $\begin{array}{l}\text { High rates of Charging and } \\
\text { discharging }\end{array}$ & $\begin{array}{l}\text { Low amount of energy stored (3- } \\
5 \mathrm{Wh} / \mathrm{kg} \quad \text { vs. 30-40Wh/kg for } \\
\text { batteries }\end{array}$ \\
2 & $\begin{array}{l}\text { Higher lifecycle }(>500,000 \\
\text { rechargeable batteries can only } \\
\text { reach 10,000) }\end{array}$ & $\begin{array}{l}\text { Still requires sophisticated control } \\
\text { and switching equipment }\end{array}$ \\
3 & $\begin{array}{l}\text { Good reversibility } \\
4\end{array}$ & Low toxicity of material used \\
5 & High cycle efficiency \\
6 & $\begin{array}{l}\text { Low internal resistance (higher } \\
\text { output power) }\end{array}$ \\
7 & Extremely low heating levels \\
8 & $\begin{array}{l}\text { High and very low working } \\
\text { temperatures and stable }\end{array}$ \\
\hline
\end{tabular}

\subsection{Carbon Nanomaterials for Manufacturing Ultracapacitors}

Carbon nanomaterials can be used in the manufacturing of ultracapacitors because of their novel properties. They have high surface area that is essential for greater energy stored. They have also high breakdown voltage for higher energy efficiencies. The surfaces of these materials have pores that increase the surface area allowing the exploitation of the surface and promote easy diffusion of ions of the electrolyte. Carbon-based materials are the most preferred active material for the electrodes for ultracapacitors because they have the best properties at low cost such as good stability, high surface area and are readily available [8].

Besides the lightness and high surface area of the carbon-nanomaterials, the material is abundant in Zimbabwe as graphite or coal. This is a huge opportunity and advantage for the nation in terms of value addition and sustainable development. Manufacturing costs of the devices will be greatly reduced as the material is available locally.

\subsection{Graphene as Electrodes}

Since its discovery in 2004, graphene has found many applications in our modernday life and one of them is as electrode in ultracapacitors. Reduced graphene oxide (rGO) is the most used active material in the ultracapacitor because of its low cost, scalability, wet-chemical properties and high chemical active sites density. In addition 
to that, when enough water becomes entrapped in the layer of $\mathrm{rGO}$, the material becomes anisotropic ion conductor as well as an electrical insulator. This expands its applications because it can be applied in ultracapacitor manufacturing as a viable electrolyte and an electrode insulator [3]. It has also high intrinsic capacitance of $21 \mu \mathrm{F} / \mathrm{cm}^{2}$ and a large surface area of approximately $2,600 \mathrm{~m}^{2} / \mathrm{g}$, and can stand high temperatures without being chemically unstable [2].

Graphene can be manufactured by mechanical separation of graphite or by graphene sheet production by laser system.

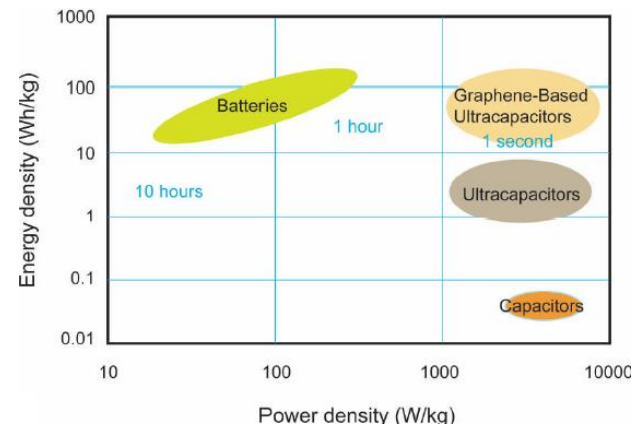

Fig. 2. Graphene Based ultracapacitors

\subsection{Carbon Nano Tubes (CNT) as Electrodes}

The have a unique structure, high surface area, low mass density, excellent chemical stability and outstanding electrical conductivity $(100 \mathrm{~S} / \mathrm{cm})$. CNTs electrodes have further advantages that they are binder free and each tube is connected directly to the substrate. Most of the CNT electrodes are mesoporous a property which can contribute to the double-layer capacitance and faster ion transportation rates [12]. The capacitance of CNT ultracapacitors that is reported in literature is $36.5 \mathrm{~F} / \mathrm{g}$ with calculated energy density of approximately $0.4 \mathrm{Wh} / \mathrm{kg}$ and a power density of approximately $1 \mathrm{~kW} / \mathrm{kg}$.

\subsection{Carbon Nano Onions (CNO) as Electrodes}

The have a unique structure, high surface area, low mass density, excellent chemical stability and outstanding electrical conductivity. The capacitance of CNOs activated by $6 \mathrm{~mol} / \mathrm{l} \mathrm{KOH}$ solution is $122 \mathrm{~F} / \mathrm{g}$ (about five times larger than inactivated CNOs) with a measured power density of $153 \mathrm{~kW} / \mathrm{kg}$ and an energy density of 8.5 $\mathrm{Wh} / \mathrm{kg}[2]$.

\subsection{Other Carbon Materials as Electrodes}

Activated Carbon and Carbon Aerosols 


\section{Conclusion}

Better energy storage can boost up the solar technology and make it affordable for developing countries like Zimbabwe. This is a mini review of the technology development, storage and application. There is still ongoing research to improve these devices, and it is being shown that a mixture of materials can give rise to good and improved properties to enhance energy storage and discharge and life cycle. These newer and safer ways of storing and discharge electrical energy like ultracapacitors can be a viable pathway to a greener energy security for the country.

\section{References}

1. G. Xiong, "A Reveiw of Graphene-Based Electrochemical Microsupercapacitors," Electroanalysis, vol. 26(1), no. 30-51, (2014).

2. NASA, "Graphene-based Filters and Supercapacitors for Space and Aeronautical Applications," Cancun, 2015

3. G. Yang, Z. Yun Shen and Q. X. N. H. Min, "Chemical activation of carbon nano-onions for high-rate supercapacitor electrodes," Carbon 51, no. 52-, 2013.

4. D. Nangia, S. Niranjan and Y. Chauhan, "Potential of Solar Thermal Technology and its Status in India," Emerging Technology abd Advanced Engineering, 2014.

5. Johannes Stierstorfer, "Solar Generation," Greenpeace Internation, Amsterdam, 2006.

6. Q. Volker and M. Muriel, "Solar Power - Photovoltaics or Solar Thermal Power Plants?," Brussels, 2001

7. J. Gwamuri and S. Mhlanga, "Design of PV Solar Home System for Use in Urban Zimbabwe," Applied Physics and Radiography, 2008

8. P. Sharma and T. Bhatti, "A Review of Electrochemical Double Layer Capacitors," Energy Conversion and Management, vol. 12, no. 2901-2912, 2010

9. P. Johansson and B. Andersson, "Comparison of simulation programs for supercapators modelling," Sweden, 2008

10. Green Energy. [Film]. USA: NOVA, 2008

11. CNN. [Film]. USA: CNN, 2015.

12. EuroNanoForum, "Graphene based electrodes for high perfomance supercapacitors," 2015.

13. J. Lee, "Modeling of the Electrical and Thermal Behaviors of an Ultracapacitors," Energies, vol. 7, no. 8264-8278, 2012.

14. M. Halper and J. Ellenbogen, "Supercapacitors: A brief overveiw," Virginia, USA, 2006. 